\title{
Aeromagnetic data analysis for the identification of concealed uranium deposits: a case history from Singhbhum uranium province, India
}

\author{
S. P. Anand and Mita Rajaram
}

Indian Institute of Geomagnetism, New Panvel, Navi Mumbai, 410 218, India

(Received January 23, 2006; Revised April 28, 2006; Accepted May 1, 2006; Online published September 16, 2006)

\begin{abstract}
Aeromagnetic data over a part of the Singhbhum uranium province, India, within the framework of 'Operation Hard Rock' have been analyzed. The aeromagnetic anomaly map, its analytic signal amplitude, the Euler solutions and apparent susceptibility map helped in identifying the nature and depth of the magnetic sources in the study region. The Singhbhum Shear Zone is clearly delineated. The location of the mined uranium deposits coincide with the shallow magnetic sources. The present study also identified distinctive magnetic sources between the Dalma Volcanics and the Chotanagpur Granitic Gneissic Complex that suggest the presence of a sub-surface shear. The magnetic sources in this newly identified shear zone lie at a depth of $200 \mathrm{~m}$ and depict a similar magnetic signature and susceptibility as those of the Singhbhum Shear Zone where uranium is being mined. This shear could be the subsurface contact between high-grade metamorphic rocks (amphibolite facies) to the north and the greenschist facies low-grade metamorphics to the south. This shear zone, also characterized by radiometric anomalies, possibly indicates a zone of concealed uranium deposit that can be explored in the future. The present analysis shows the importance of aeromagnetic surveys and its utility in exploration for concealed mineral deposits.
\end{abstract}

Key words: Magnetic anomalies, tectonics, magnetite, potential field, analytic signal, Euler deconvolution.

\section{Introduction}

The demand for energy is growing globally, and it is necessary to apply innovative techniques to explore for all viable resources to meet this growing need. Uranium is a key element in the generation of Nuclear Power, and one needs to explore different methods to recognize uranium provinces. The Singhbhum region, located in the northeastern part of the Indian sub-continent, has rich resources of metallic as well as non-metallic minerals. This region contains rich deposits of copper, iron, manganese and chromium and workable deposits of uranium and vanadium. The literature recognizes this area as as a region of polymetallic mineralization, denoting it as the Singhbhum uranium province (SUP). Two distinctive types of uranium mineralization occur in the SUP: (1) early quartz-pebbleconglomerate type and (2) shear-controlled hydrothermal type (Mahadevan, 1988). The country's main uraniumproducing mines, which exploit the second type of mineralization, are located on the mapped Singhbhum Shear Zone (SSZ). Hence, the delineation of faults/shear zones, either exposed or under cover, forms the primary step for the identification of uranium deposits. Further, the uranium ore of Singhbhum is known to contain relatively large amounts of magnetite, so much that there is a magnetite recovery plant in Singhbhum which after the extraction of uranium, processes that tailings through magnetic separators, so that the fine magnetite can be used in coal washeries (Gupta,

Copyright (c) The Society of Geomagnetism and Earth, Planetary and Space Sciences (SGEPSS); The Seismological Society of Japan; The Volcanological Society of Japan; The Geodetic Society of Japan; The Japanese Society for Planetary Sciences; TERRAPUB
2004). It is this presence of magnetite in the uranium ore of Singhbhum that suggests the use of magnetic methods as a tool for exploration of uranium. Magnetic anomalies in a region are interpreted to delineate areas of focused fluid flow (David et al., 2000) and hence are potentially valuable markers for mineral exploration. The magnetic method has been used extensively for the exploration of minerals but there is very little mention in the literature of its use for the exploration of uranium.

Uranium ore occurs in several structural settings within igneous, metamorphic and sedimentary rocks of various geological ages. Chlorite-quartz schist with magnetite and apatite, belonging to the early Proterozoic-late Archaean Age, is the most common host for mineralization (Pandey et al., 1994). The magnetite-apatite bodies are believed to be products of interaction between chlorite schist derived by metamorphism of basic rocks and migmatizing solutions (Barnes et al., 1981). As uranium mineralization is closely associated with magnetite, the analysis of aeromagnetic data can play a crucial role in the identification of concealed uranium deposits. For commercially viable uranium ores one needs to locate near-surface ore deposits, and high-resolution aeromagnetic surveys from low-altitude aircraft could provide vital information for this. As a part of the mineral exploration program, high-resolution airborne magnetic and radiometric data have been collected over the SUP and the adjoining regions within the framework of the 'Operation Hard Rock' (OHR) program, which is jointly conducted by the Atomic Minerals Division (AMD) and the Geological Survey of India (GSI). The analysis of magnetic data is complicated and, therefore, magnetic data have 
very often remained underutilized. In the present paper, part of the magnetic data collected over SUP within the framework of OHR has been analyzed to study the magnetic signatures associated with the shear-controlled, hydrothermal type uranium mineralization and the information obtained extrapolated to interpret similar structures and identify plausible regions of concealed uranium deposits that could be explored in the future.

\section{Generalized Geology}

The Singhbhum Craton (SC) is located in the eastern part of the northern Peninsular Shield of India between latitudes $21-23^{\circ} 15^{\prime} \mathrm{N}$ and longitudes $84-87^{\circ} 30^{\prime} \mathrm{E}$. A generalized geology and tectonic map of the SUP, redrawn from Mahadevan (1988) is shown as Fig. 1 (location shown in inset) and the region under study is delineated. The SSZ separates dif-
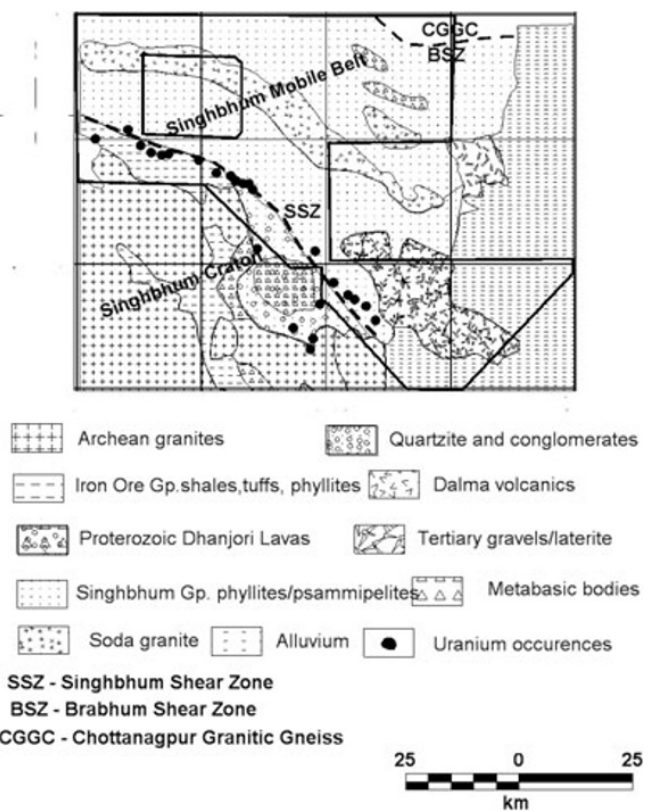

Fig. 1. Geological map of the study region redrawn from Mahadevan (1988) with uranium occurrences marked. The region under study is demarcated. Inset shows location of study region on the map of India.

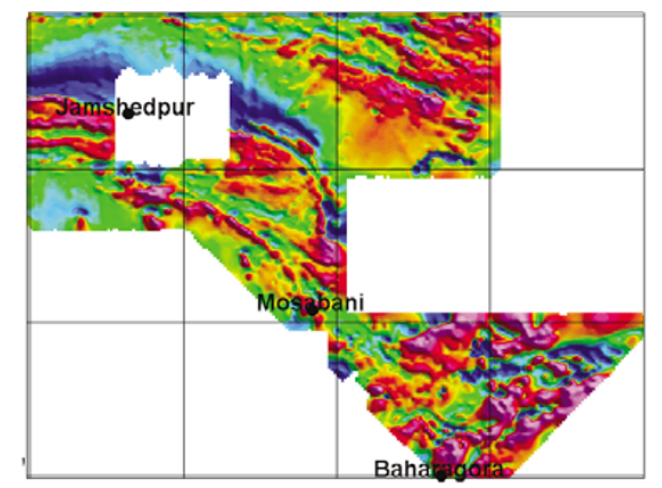

$2 \underline{\underline{5}}$

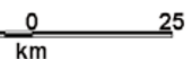

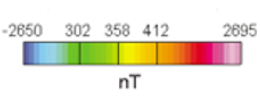

Fig. 2. Image map of the total field anomaly derived from aeromagnetic data. ferent grades of metamorphic rocks to the north and south. The SUP consists of three major tectono-stratigraphic units: the Archean granitic SC, bounded to the north by the highly folded metavolcanic and meta-sedimentary formations of the Singhbhum Group; the Chotanagpur Granitic Gneissic Complex (CGGC) still further north. The Dalma Lavas, made up of basic to ultrabasic flows, occur centrally in the Singhbhum Group. The Singhbhum Group had a complex crustal evolution in the Proterozoic and has been described as the Northern Singhbhum Mobile belt (SMB) (Saha, 1994; Mahadevan, 2002 and references therein). The SMB consists of the high-grade Chaibasa and Dhalbhum formations between the SSZ and Dalma Volcanics, with a low- to medium-grade volcano-sedimentary belt between the Dalma range and the CGGC. Two major shear zones, including the SSZ and the Barabhum Shear Zone (BSZ), dissect the SUP and are of interest from the point of view of metallogeny. The SSZ is an arcuately disposed shear zone of deep-seated fractures, acid and basic volcanism and hydrothermal metasomatic activity. The shear zone has been active over a long period of time, possibly from late Archaean through to the Proterozoic (Saha, 1994), and has been the locus for polymetallic and polyphase hydrothermal mineralization. The BSZ cuts across the supracrustal belt to the north of the Dalma Volcanics close to Chotanagpur migmatite-granulite belt and is relatively much less mineralized.

\section{Aeromagnetic Data and Analysis}

The Aero Service Corporation collected high-resolution aeromagnetic data over the SUP for the Atomic Minerals Division (AMD), India during 1968 and 1969. The original data were collected at a flight altitude of 61-122 m with a flight line spacing of $500 \mathrm{~m}$ in the region covering a surface area of approximately $3800 \mathrm{~km}^{2}$. Jamshedpur is an industrial city and to avoid the associated cultural noise data were not colleted over Jamshedpur; consequently, there is a
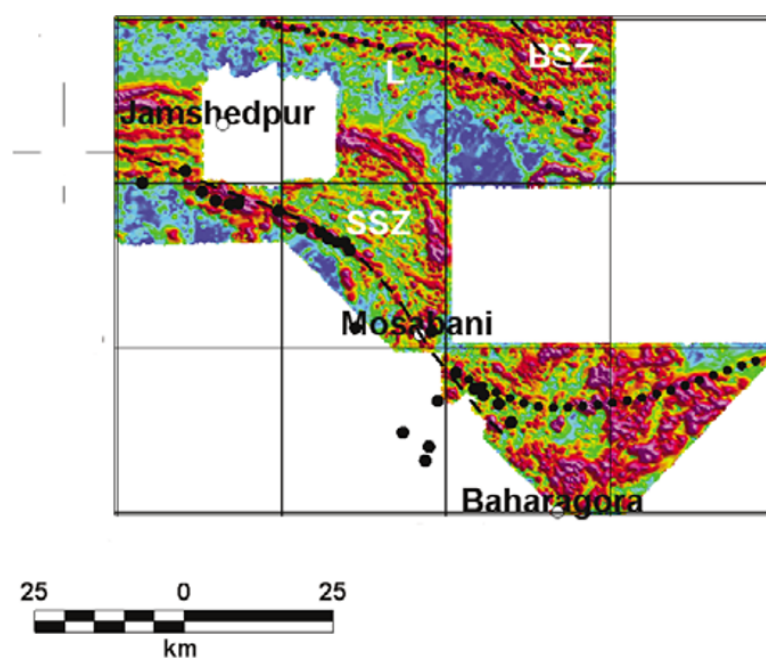

Fig. 3. Plot of the analytic signal amplitude map of the magnetic anomaly. Warm red color represents highs and cool colors represent lows. Highs represent magnetic sources. Location of uranium occurrences is shown as dots. SSZ: Singhbhum Shear Zone; BSZ: Barabhum Shear Zone is superposed. L represents newly identified shear zone. 
data gap. The available aeromagnetic maps corrected for the main field (Anand and Rajaram, 2004) using Definitive Geomagnetic Reference Field (DGRF) model 1970 (IAGA, 1981) corresponding to the epoch and altitude of survey were re-gridded at 250-m intervals and merged (Johnson et al., 1999) to form the aeromagnetic anomaly map of the region (Fig. 2).

The aeromagnetic anomaly map (Fig. 2) depicts several short wavelength anomalies embedded in a smoothly varying background. The magnetic fields of the major geological formations in the area are distinctive, and the magnetic trends show remarkable conformity to the structural trends. The most prominent feature in the anomaly map is the SSZ, which represents itself as a curvilinear feature south of Jamshedpur and continuing southeast until it abuts against the NE-SW trending anomalies north of Baragorah. There is an excellent correlation between the expression of the SSZ in the aeromagnetic map and the airborne radiometric anomalies (Mahadevan, 1988). The NE-SW

(a)
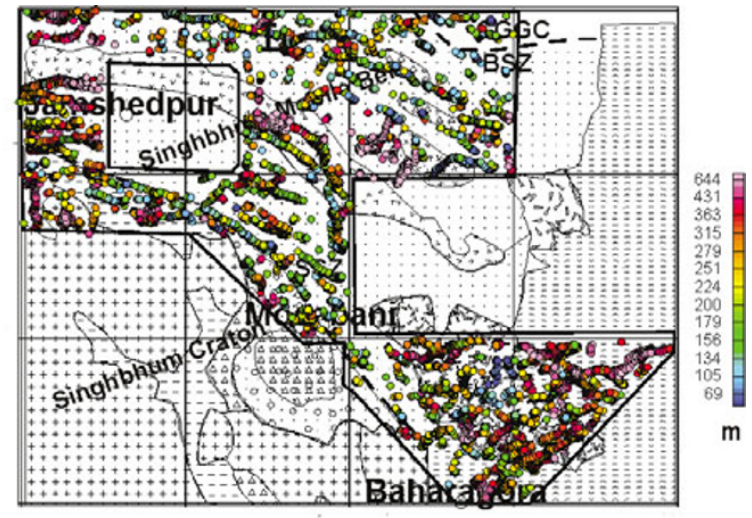

25

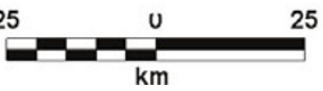

(b)

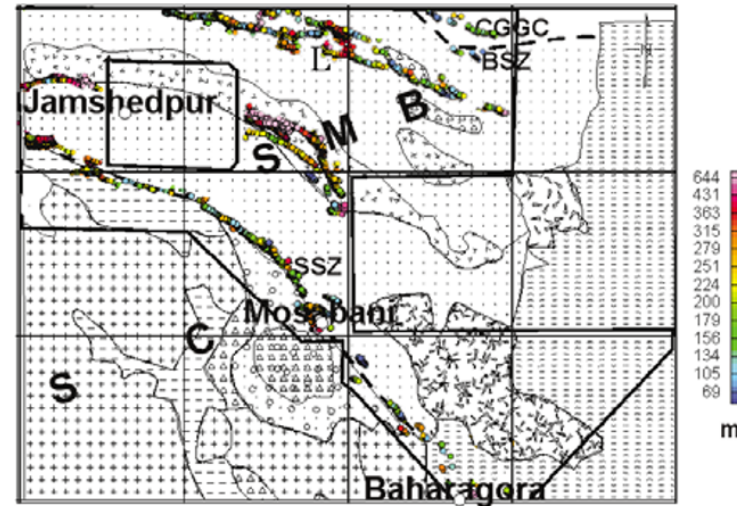

25

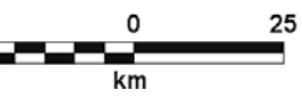

Fig. 4. (a) Plot of the Euler solutions of the magnetic anomaly (window length ten and structural index one representing linear intrusives) superposed on the geology map (Fig. 1). The depth estimates of the Euler solutions are depicted in the color scale bar in meters. (b) Plot of the Euler solutions (selected from Fig. 4(a)) depicting the linear trends of SSZ and the newly identified shear zone (L) superposed on the geology map (Fig. 1). trending anomalies have large amplitudes and occur over Tertiary gravels and alluvium that cannot account for such high anomalies. It has been inferred that highly susceptible magnetic rocks underlying the gravel and alluvium can possibly be the extension of the Dhanjori lavas (Fig. 1) beneath the sedimentary cover. The linear high-low paired anomaly running parallel to $22^{\circ} 45^{\prime} \mathrm{N}$ is the magnetic signature of the Dalma Volcanics (Fig. 1). Several linear anomalies are evident in the northeastern part of the image map. These probably represent shear zones and associated magnetic minerals, both exposed and under cover. One of the linear anomalies is a weak representation of the BSZ, separating the SMB from the Chotanagpur migmatite-granulite belt. A prominent linear anomaly observed northeast of the Dalma Volcanics within the SMB can be related to a subsurface structure, as it does not have any surface manifestation. The radiometric anomaly map (Mahadevan, 1988) also shows a considerable number of anomalies in this region.

To define the distribution of magnetic sources in the study area an analytic signal amplitude map (Roest et al., 1992) was prepared. Although the analytic signal amplitude of three-dimensional features does not have the same identical properties as the analytic signal amplitude of twodimensional features $(\mathrm{Li}, 2006)$, in the present study most of the features studied are linear and the method of Roest $e t$ al. (1992) is considered to be appropriate. The analytic signal amplitude is useful in locating the edges of magnetic source bodies, particularly where remanence and/or low magnetic latitude complicates interpretation. The maxima of this function mark the edges of the magnetized bodies, particularly for two-dimensional sources, regardless of the direction of magnetization and are related to source depths (MacLeod et al., 1993). The short wavelength magnetic sources in the study region are emphasized in the analytic signal amplitude map (reproduced as Fig. 3) on which are superposed the mapped uranium occurrences taken from Mahadevan (1988). The SSZ and BSZ are superposed on the analytic signal amplitude map. The magnetic sources are clearly concentrated along the arcuate-shaped SSZ and also on the small part of the BSZ that falls within the study area. West of Jamshedpur, there are a series of parallel E-
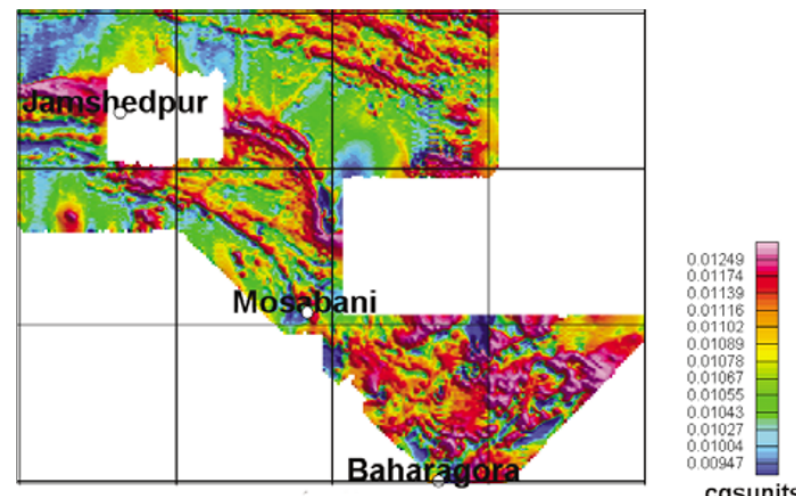

Fig. 5. Plot of the apparent susceptibility map of SUP at a depth of $100 \mathrm{~m}$ for the ambient geomagnetic field, $\mathrm{F}=45,200 \mathrm{nT}\left(\mathrm{I}=30.29^{\circ}\right.$, $\mathrm{D}=-0.92^{\circ}$ ). 
W linear sources falling within the high-grade ChaibasaDhalbhum formations and the Dalma Volcanics. The data gap at Jamshedpur makes it difficult to map the exact continuation of the sources to the east. A very striking feature in Fig. 3 is the long linear WNW source (L) north of the Dalma Volcanics, which is also associated with radiometric anomalies (Mahadevan, 1988) and which has similar magnetic characteristics as the SSZ.

The depth to the top, location and the nature of the magnetic sources has been calculated using the threedimensional Euler Deconvolution (Reid et al., 1990). The apparent depth to the magnetic source is derived from Euler's homogeneity equation (Euler deconvolution). This process relates the magnetic field and its gradient components to the location of the source of an anomaly, with the degree of homogeneity expressed as a "structural index". The structural index (SI) is a measure of the fall-off rate of the field with distance from the source. Euler solutions have been calculated for different structural indices $(0,0.5$, $0.75,1,1.25,1.5,2,3)$, and the best clustering of solutions were obtained for the structural index one, which represents linear intrusive sources. The Euler solutions for $\mathrm{SI}=1$ are shown in Fig. 4(a) superposed on the geology map. All of the solutions obtained are plotted. The plot of the selected Euler solutions related to SSZ, BSZ and L are shown in Fig. 4(b). It would appear from the Euler solutions that the magnetic sources in the region covered by the Tertiary gravel and alluvium are the deepest. The magnetic sources in the shear zones are shallow, having an average depth of $140 \mathrm{~m}$ in SSZ and $200 \mathrm{~m}$ along L. Thus, the present study suggests that the shear zones are associated with rocks that have a high magnetic mineral content and occur at shallow depths.

Susceptibility mapping is an analytical process in which the observed magnetic field is directly inverted into a susceptibility contrast distribution (Grant, 1973, 1974; Silva and Hohmann, 1984). Apparent susceptibility mapping is a combination of linear filters that perform a reduction to the pole and downward continuation to the source depth, corrected for the geometric effect of a vertical square-ended prism; this is then divided by the total magnetic field to yield susceptibility (Yunsheng et al., 1985). Calculation of the apparent susceptibility map assumes that the magnetic field has been corrected for the IGRF, that magnetization is by induction only and that all magnetic responses are caused by a collection of vertical square-ended prisms of infinite depth extent. For calculating the apparent susceptibility contrast, the data were continued down to a source depth of $100 \mathrm{~m}$ and an ambient geomagnetic field of strength $45,200 \mathrm{nT}$, an inclination of $30.29^{\circ}$ and a declination of $-0.92^{\circ}$ of the study region during $1968-1969$ have been utilized for reducing to the pole. Since the real earth situations differ from the ideal assumptions, the outcome of the process is labeled as "apparent susceptibility $\left(K_{A}\right)$ map". An apparent susceptibility map (Fig. 5) has been computed to obtain an idea of the relative $K_{A}$ values in the shear zones. It was found that the average apparent susceptibility contrast of the magnetic sources along SSZ and L was of the order of 0.1533 SI units, indicating that the sources in both these lineaments are very similar. From Clark (1997), such large values of susceptibility are associated with magnetite. Thus it is confirmed that the shear zones are associated with rocks that have high magnetite content that occur at shallow depths. We find that the magnetic sources as evident on the analytic signal amplitude map (Fig. 3) correlate with high apparent susceptibility (Fig. 5).

\section{Discussion}

Analysis of the high-resolution aeromagnetic data over the SUP helps identify the magnetic sources and their depth extent. The magnetic sources are mainly associated with the SSZ, and we believe that this is due to the magnetite present in this shear zone as accessory minerals in the rocks hosting uranium mineralization at Singhbhum. The mapped uranium deposits are superposed on the analytic signal amplitude map (Fig. 3), and it can be seen that magnetic sources lie along the mapped uranium deposits, consistent with the known geological associations. This is also supported by the Euler deconvolution, which gave very good solutions for structural index one, representing intrusives along the shear zone. However, it is interesting to note that the Euler solutions are very shallow on the mapped uranium deposits.

In the present scenario, it is well known that the SSZ is the contact between SC to the south and the highly metamorphosed rocks of the SMB. A similar WNW-trending magnetic source $(\mathrm{L})$ is evident on the northeastern side of Fig. 3 to the north of the Dalma Volcanics. Euler solutions (Fig. 4(b)) also depict a tight cluster along L, and the depths are comparable with that for the SSZ, suggesting a subsurface fault/shear zone. This subsurface shear/fault has not been identified to date and could possibly be the subsurface contact (shear) between high-grade metamorphic rocks (amphibolite facies) to the north and the greenschist facies low-grade metamorphics to the south within the SMB. The magnetic signature of this shear zone can be explained in terms of the magnetite formed as an accessory mineral associated with uranium mineralization, produced either as a result of strain partitioning along the contact between relatively competent units or due to the alteration of the amphibolite facies rocks due to fluid flow (David et al., 2000). During alterations due to fluid flow, oxidation of ferrous iron-bearing minerals occurs due to oxidation by mineralizing fluids (McMillan, 1997). Three broad transitional zones have been recognized within this domain. According to Barnes et al. (1981) "Uranium deposits related to the lower-middle Proterozoic Unconformity generally occur immediately below an unconformity within structural shear or fault zones along which amphibolite-grade rocks have commonly undergone retrograde metamorphism to chlorite-bearing assemblages". We therefore conjecture that the central zone may mark the transition into chloritesericite phyllite and magnetite-bearing biotite phyllite (Mahadevan, 2002). The sources responsible for the magnetic anomalies along SSZ are the apatite-magnetite veins. The apparent susceptibility map reveals that the sources along SSZ and L have susceptibilities close to 0.1533 SI units, suggesting that the same materials acts as magnetic carriers in these two shear zones; it is thus inferred that the newly identified shear zone (L) also hosts apatite-magnetite veins. This is further confirmed from Clark's (1997) ta- 
ble, which suggests that such high values of susceptibility are related to the magnetic mineral-magnetite. The airborne radiometric anomalies (Mahadevan, 1998) exhibit an excellent correlation between the expressions of the shear zones in the aeromagnetic map. Since the magnetic signatures of the newly identified shear zone are similar to that of the SSZ where uranium is being mined and the rocks have undergone amphibolite facies metamorphism (Mahadevan, 1988), the probability of uranium deposits occurring along this shear are fairly high at an average depth of $200 \mathrm{~m}$, represented by the Euler solutions. This is also supported by the abundance of radiometric anomalies (Mahadevan, 1988) along this zone.

From the above it is evident that high-resolution aeromagnetic data, if analyzed judiciously, can be a potent tool for unraveling structures in the sub-surface. The present paper deals only with around $30 \%$ (available with us) of the data set covered within the framework of OHR. An analysis of the entire OHR data set could provide valuable insights, especially in terms of the continuation of the shear zones and their depth extent, and this, in turn, could give new insights in locating valuable mineral deposits in the SUP. Further, similar exercises could be undertaken in different regions around the globe with a similar structural setting for the identification of viable uranium resources.

Acknowledgments. The authors express their sincere gratitude to Dr. T. M. Mahadevan, Former Director, Atomic Minerals Division, Hyderabad, for providing the aeromagnetic data used for the present analysis.

\section{References}

Anand S. P. and Mita Rajaram, Identification of Uranium deposits through analysis of aeromagnetic data over Singhbhum, Exploration and research for Atomic Minerals, (a publication of the Atomic Minerals Directorate for exploration and research, India) 15, 121-126, 2004 (Papers presented in the workshop on "Geophysical Techniques for Exploration of concealed uranium deposits", held at AMD, Hyderabad).

Barnes, H. L., S. S. Adams, and A. W. Rose, Ores formed by diagenetic and metamorphic processes. Mineral Resources: Genetic Understanding for practical applications, in Studies in Geophysics, National Academy Press, Washington D.C., 1981.

Clark, D. A., Magnetic petrophysics and magnetic petrology: aids to geological interpretation of magnetic surveys, AGSO J. Aust. Geol. Geophys., 17(2), 83-103, 1997.
David, W. M., G. M. Gibson, and J. W. Giddings, Regional structure and distribution of magnetite: implications for the interpretation of aeromagnetic data in the Broken Hill region, New South Wales, Explor. Geophys., 31, 8-16, 2000.

Grant, F. S., Magnetic susceptibility mapping: The first years experience: Abstract presented at 43rd Annual International Meeting, Society of Exploration Geophysics, Mexico City, 1973.

Grant, F. S., Magnetic susceptibility map with accompanying notes: Open file report, 229(A), Geological Survey of Canada, 1974.

Gupta, R., UCIL-Towards sustainable supply of fuel for Nuclear power, Int. J. Nucl. Power, 18, 58-60, 2004.

IAGA Division 1 Working Group 1, International Geomagnetic Reference Fields: DGRF 1965, DGRF 1970, DGRF 1975, and IGRF 1980, EOS Trans. $A G U, \mathbf{6 2}, 1169,1981$.

Johnson, A., S. Cheeseman, and J. Ferris, Improved compilation of Antarctic Peninsula magnetic data by new interactive grid suturing and blending methods, Ann. Geophys., 42, 249-259, 1999.

Li, X., Understanding 3D analytic signal amplitude, Geophysics, 71, L13L16, 2006.

MacLeod, I. N., K. Jones, and T. T. Dai, 3D Analytic signal in the interpretation of total magnetic field data at low magnetic latitudes, Explor. Geophys., 24, 679-687, 1993.

Mahadevan, T. M., Recognition of Uranium Provinces, Proc. Tech. Committee Meeting, International Atomic Energy Agency Vienna, 337-369, 1988.

Mahadevan, T. M., Geology of Bihar and Jaharkhand, Text Book Series, Geological Society of India, Bangalore, 2002.

McMillan, R. H., Unconformity associated U, in Geological Field Work 1997, British Columbia Ministry of Employment and Investment, 19981,24,G1-G4, 1997.

Pandey, P., P. Kumar, and L. D. Upadhyay, Uranium Deposits of TuramdihNandup area, Singhbhum District, Bihar and their Spatial relationship, Abstract. Explor. Res. Atomic Minerals, 7, 1994.

Reid, A. B., J. M. Allsop, H. Granser, A. J. Millett, and W. I. Somerton, Magnetic interpretations in three dimensions using Euler deconvolution, Geophysics, 55, 80-91, 1990.

Roest, W. E., J. Verhoef, and M. Pilkington, Magnetic interpretation using 3D analytic signal, Geophysics, 57, 116-125, 1992.

Saha, A. K., Crustal Evolution of Singhbhum North Orissa Eastern India, Mem. Geolog. Soc. India, 27, 1994.

Silva, J. B. C. and G. W. Hohmann, Airborne magnetic susceptibility mapping, Explor. Geophys., 15, 1-13, 1984.

Yunsheng, S., D. W. Strangway, and W. E. S. Urquhart, Geological interpretation of a high-resolution aeromagnetic survey in the AmosBarraute area of Quebec, in The Utility of regional gravity and magnetic anomaly maps, edited by W. J. Hinze, Society of Exploration Geophysicist, pp. 413-438, 1985.

S. P. Anand and M. Rajaram (e-mail: mita@iigs.iigm.res.in) 